\title{
NOVEL MODEL FOR INTEGRATIVE MEDICINE CURRICULUM
}

\section{Carl Camelia ${ }^{1}$, Sateesh Babu Arja *2, Kumar Ponnusamy ${ }^{2}$, Nimra Deivassagayame ${ }^{2}$.}

${ }^{1}$ Universidad Maharishi de Latino America y el Caribe (UMLAC), Willemstad, Curaçao;

Universidad Integral del Caribe y América Latina (UNICAL), Willemstad, Curaçao.

${ }^{* 2}$ Avalon University School of Medicine (AUSOM), Willemstad, Curaçao.

\section{ABSTRACT}

\begin{abstract}
While the use of Traditional, Complimentary, and Integrative Medicine (TCIM) is substantial, it continues to exist at the periphery of allopathic medicine. This article provides a global scenario with the strengths and weaknesses of the present health care systems. Availability, affordability, and accessibility of healthcare coupled with uneven growth and the double burden of diseases have become major concerns around the globe. This article emphasizes the need for mindset change from illness-disease-drug centric curative to person-healthwellness centric preventive and promotive approaches. It highlights the innovation deficit faced by conventional allopathic medicine and delineates the significant benefits of the integration of conventional medicine with traditional, complementary and integrative therapies in the medical curriculum.

Medical heterogeneity is a rising trend, and people are trying to explore various options, including allopathic, complementary, and alternative medicine. In such a situation, knowledge from Yoga, Ayurveda, Traditional Chinese medicine/Acupuncture, and Homeopathy may play a vital role. We can progress with an appropriate model by integrating allopathic medicine with traditional medicine systems for affordable health care. Several medical scientists have contributed positive reflections and benefits of integrative approaches to health. These provide not only clear insight into the historical roots of the healing traditions of traditional and complementary medicine, but also into the entire concept of integrative approaches to health.

KEYWORDS: Integrative Medicine, Complementary Medicine, Alternative Medicine, Conventional Medicine, Traditional Medicine, Maharishi Ayurveda, Medical Education.
\end{abstract}

Address for correspondence: Dr. Sateesh B. Arja, M.B.B.S, MHPE, MSPH, FAMEE, SFHEA, FAcadMEd, FIAMSE, Director of Clinical Skills and Executive Dean, Avalon University School of Medicine(AUSOM), Willemstad, Curaçao. Phone number-005-999-6965682

E-Mail: sarja@avalonu.org

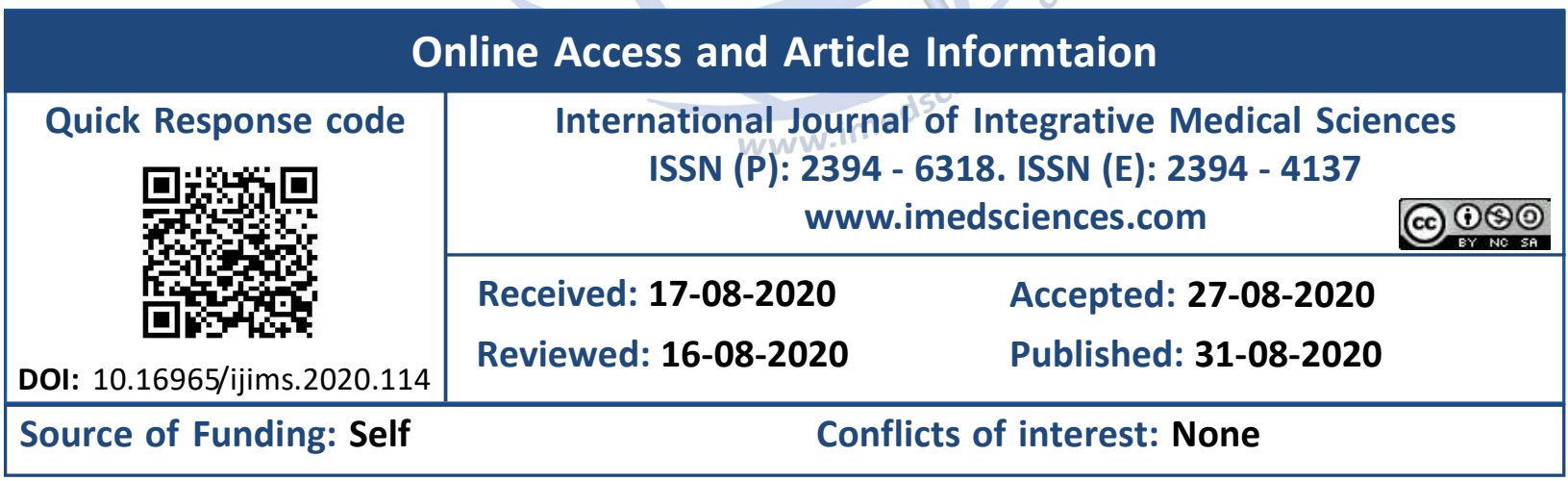

\section{INTRODUCTION}

Conventional Medicine: Conventional allopathic and osteopathic medicine is medicine as practiced by holders of M.D. (Doctor of Medicine) or D.O. (Doctor of Osteopathy) degrees and other health professionals, such as physiotherapists, registered nurses, and psychologists. Other terms for conventional medicine include allopathy, or western, orthodox, and biomedicine. Some conventional medical practitioners also practice Traditional, Complimentary and Integrative Medicine (TCIM). For instance, the
Ohio State University College of Medicine, Columbus, Ohio (United States), has developed an innovative course combining Ayurveda and Yoga, specially conceived for the Western audience [1].

Traditional, Complementary Alternative and Integrative Medicine: The term Complementary and Alternative medicine (CAM) defines a collection of health care practices, products, and systems not currently considered to be a part of allopathic medicine [2]. 
According to National Center for Complementary and Integrative Health $(\mathrm{NCClH})$ of the National Institute of Health (NIH) of the USA, CAM approaches to health are also called Complementary and Integrative Health, describing integrative health as conventional and complementary approaches brought together in a coordinated way [3, 4].

The World Health Organization (WHO) refers in this regard since mid-2017 officially to Traditional, Complementary and Integrative Medicine (TCIM), defining Traditional Medicine as the sum total of the knowledge, skill, and practices based on the theories, beliefs, and experiences indigenous to different cultures, whether explicable or not, used in the maintenance of health as well as in the prevention, diagnosis, improvement or treatment of physical and mental illness. Typical traditional medicine approaches that according to WHO are being used worldwide are Ayurveda, Traditional Chinese Medicine and Unani medicine [5].

While systems of TCIM such as Ayurveda, chiropractic, naturopathy, and homeopathy show considerable variety, they share many of the same fundamental values [6]. CAM systems are considered by an all-inclusive and highly adapted approach to patient care, an emphasis on maximizing the body's intrinsic curative ability, involving patients as active members in their care, addressing mental, physical, and spiritual attributes of disease, and placing a strong emphasis on preventative medicine $[7,8,9]$.

Global Scenario: The last century has been very remarkable and unique in the entire history of medical sciences. In fundamental sciences, the discovery of DNA double helix, and completion of Human Genome Project were achievements that had no parallel. In diagnostics, technologies like Magnetic Resonance Imaging (MRI) and Positron Emission Tomography (PET) scan added brightest feathers ever to our caps. In surgery, bypass, transplants, and prosthetics changed life expectancies upwards dramatically. In therapeutics, chemotherapy and new drugs like selective serotonin reuptake inhibitors revolutionized longevity and quality of life. The Human Genome Project has opened a newer understanding of genomics, and epigenomics are progressing towards personalized medicine.
New technologies, including stem cells, molecular medicine, epigenetics, robotics, and nanotechnology, open exciting new opportunities.

Still, developing countries are confronted with disproportionate population growth, the double burden of diseases, and increasingly unaffordable healthcare expenses. Leaders, policymakers, and scholars all over the world are grappling with possible solutions to these complex, not just complicated problems. Because there is no magic bullet or no single solution [10], integration of Traditional Medicine (TM) and modern medicine may offer a solution provided, both systems respect and trust each other.

Ayurveda in Health and Disease: "Allopathy, Ayurveda, Siddha, Sowa rigpa, Unani, Naturopathy, Homeopathy, and Yoga" can be seen in India [11]. Ayurveda, India's natural health care tradition, is the comprehensive healthcare system that has been practiced in India for more than 5000 years. It is a specialized system of medicine that covers all medical fields and surgery. The historical evolution and development of Ayurveda, ancient Ayurvedic texts, specialties, and its concepts of disease etiology (vata, pitta, kapha, dhatus, mala, gunas, manasik, and saririk prakriti) have been detailed. At its core, Ayurveda has a unique way of classifying the human population based on individual constitution or prakriti. The resulting Ayurvedic 'tridosha' theory identifies principles of motion (vata), metabolism ( $p i t a)$, and structure (kapha) as discrete phenotypic groupings.

Ayurveda defines health in a much broader manner as "Prasanna atma-indriyamana" where body, mind and spirit are in the state of homeostasis, happiness, or bliss. Compare on the other hand, the WHO's definition of health as a state of complete mental, physical, and social wellbeing and not merely the absence of sickness or infirmity. Perhaps, because of proper objective ways to measure 'well-being,' the general absence of disease or infirmity has been considered to be 'health'. In many parts, the terms 'health 'and 'medicine' are actually used as synonyms. There are medicines and surgeries in allopathic medicine to treat diseases or infirmity, but not that much for attaining health. To attain health, an individual has to actively 
participate in the process. Western Medicine identifies four factors, which determine 'health'. Nutrition, lifestyle, environment, and genetic factors are the key determinants of health, which are like four pillars. When anyone becomes weak, a support system is needed as treatment or health care services. Such a curative approach in contrast to promotion and prevention strategies remains one of the main causes of deteriorating 'health' conditions.

The preventive-oriented approach of Ayurvedic etiology recognizes according to the basic textbook of Ayurveda, Charaka Sutrasthan, verse 1.54, three basic causes of disease, including overuse - underuse and - wrong use of mind, senses and time. Misuse of the mind is called Pragyaparadh: Mistaken intellect, the intellect that has lost the memory of its source, the Samhita, and which due to his 'memory loss' violates the laws of nature through all thought, speech and action. Pragya-aparadh is the root cause of all diseases. Improper use of the senses, Asatmya Indriya Artha Samyoga, may be explained as unwholesome contact between the senses and their objects. Not-correct use of time finally, Kala Parinama, is irregularities in the seasons, the cycles of nature, mistakes in lifestyle.

The disparity in health care delivery related to both quality and affordability has become a matter of great concern for world polity [12]. Innovation deficit, not just pharmaceuticals, but also in healthcare delivery, has become a serious issue for policymakers [13] more in a positive sense as a part of a healthy lifestyle.

Ayurveda and Yoga: The UN resolution helped to reintroduce Yoga to the modern world and significantly enhanced its awareness. The increased global visibility of Yoga has generated much expectation. An integral approach of Yoga and Ayurveda, together with effective elements of other health sciences, can transform healthcare and the practice of modern medicine [14]. Despite their essential unity, current approaches to education, pedagogy, curricula, practice, and research of Yoga and Ayurveda often ignore their integral and fundamental interrelationships. Today, Yoga is widely practiced and has grown exponentially into a multi-billiondollar industry; however, its essence is most often overlooked. Practitioners of Yoga generally avail themselves of only a fraction of its vast possibilities. Yoga is often limited to a lifestyle intervention or a behavioral therapy through a package dominated by physical movements and poses. Lamentably, Yoga also suffers from distortions into a plethora of versions and proprietary branding and variations that are, in large part, the result of marketing goals. The more profound meaning and purpose of Yoga practice is described in the Yoga Sutras from Patanjali-the classic text of Yoga, from where all the classic meditative traditions come, as: "Yoga (the meditative state, the experience of inner silence, inner unity) is the complete settling of the activity of the mind."

While the fundamental and valuable principles of Ayurveda are widely recognized, currently, on a global scale, the practice of Ayurveda is marginal, the exception being within the Indian subcontinent; even in India, the focus is mainly on herbal medicines. Ayurveda education, in its theory and practice, provides very limited exposure to Yoga. Although there are cursory references in curricula, practical exposure to Yoga is rare in Ayurveda schools and colleges in India. The student of Ayurveda has no educational tools for the precepts and practice of Yoga. The artificial separation of Ayurveda and Yoga becomes even more pronounced in research, and especially in clinical practice [15].

Yoga is not a quick fix for health, but it may hold surprises for those willing to make an effort [16]. A preliminary study has established the benefits of a yoga-based regimen in relieving some symptoms and signs of carpal tunnel syndrome [17]. The effect of yoga mantras has been reported to induce favorable psychological and possibly physiological effects [18]. In a randomized controlled study on lymphoma patients, it was suggested that a yoga program is feasible for cancer patients and that such a program significantly improves sleep-related outcomes [19]. Another prospective, randomized trial compared the efficacy of anti-tuberculosis treatment showed reduced symptoms suggesting a role for yoga in the treatment of pulmonary tuberculosis [20]. The mind-body relations are getting better understanding through the research on psycho-neuroendocrinological aspects, and the 
next step appears to be its extension to a deeper understanding the concept of spirituality. Some studies related to out-of-body experiences have already been well documented and studied $[21,22]$. Thus, the ancient wisdom from yoga and Ayurveda Shastras, along with scientific advances in science and technology, is paving new ways to understand complex relationships of body-mind-spirit to shape future healthcare.

Homeopathic Medicine: According to European Committee for Homeopathy [23], homeopathic medicine enables the natural self-regulating mechanisms of mind and body to function more efficiently, in order to mobilize and reinforce the healing resources, which already naturally exist. Homeopathic medicine is based on two principles [24]. The first principle is the acceptance that 'alike cures alike', meaning that minor, extremely diluted amounts of therapeutic substances are given to treat symptoms or disease when the same substances are offered at higher or more concentrated doses cause those symptoms. The second principle states that "homeopathic remedies retain bio-logical activity after repeated dilution and succession even when diluted beyond Avogadro's number". However, after a systematic review of systematic reviews of homeopathy, Ernst [24] concludes that there is no support of evidence from systematic reviews that homeopathic medicine may produce clinical effects different from placebo or superior to other control interventions.

Traditional Chinese Medicine (TCM): TCM is the present name for an olden system of health care from China. TCM is based on a thought of balanced vital energy, that is believed to flow throughout the body. Vital energy is postulated to regulate a person's spiritual, emotional, mental, and physical balance. The disease is proposed to result from the flow of vital energy being disrupted. Among the TCM components are herbal and nutritional therapy, restorative physical exercise, meditation, acupuncture, and remedial massage.

Traditional Medicine and Drug Discovery: Researchers have documented that traditional medicines may offer better routes to the discovery, development, and delivery of new drugs with enhanced performance in terms of cost, safety, and efficacy [25]. It has been documented that the WHO's Commission on Intellectual Property and Innovation in Public Health has also recognized the promise and role of traditional medicine in drug development for affordable health solutions [26]. Countries like India, China, Korea, Malaysia, Brazil, South Africa, Australia, and the like are becoming increasingly aware of the value of their traditional knowledge. On the other hand, the global pharmaceutical industry is looking for innovative solutions to expedite the discovery process. Therefore, innovative approaches inspired by traditional knowledge like Ayurveda may aptly occupy this niche strategy to expedite the drug discovery and development process, especially in the existing global economic environment.

Ayurvedic Remedies for Diseases: Seeking new synergistic combinations and bioavailability improvements are innovative strategies that can play a significant role in drug development. To this end, we believe that the basic principles, experiential wisdom, holistic approach, and systematic database of Ayurveda may offer useful bioprospecting tools and an efficient discovery engine [25].

For instance, in animal studies, a combination of artemisinin derivative and curcumin has been reported to show a synergistic interaction in killing Plasmodium falciparum leading effectively to total survival [27]. There have been several studies on piperine showing its combination improved bioavailability of synthetic drugs such as propranolol, theophylline, and rifampicin. The clue for piperine as a bio enhancer came from Ayurveda [28]. Such bioavailability enhancing activity may have numerous advantages in drug development, including a reduction in dose, toxicity, and treatment costs.

Ayurveda and Functional Genomics: It is believed that drugs based on traditional medicine may provide a cost-effective alternative to protein-based or other biotech-based expensive therapeutics [29]. Combining Ayurveda and functional genomics in a systems biology scenario may reveal the pathway analysis of crude and active components [30]. Pharmacogenomics is now significantly influencing drug discovery, and genotyping is recommended for drugs that are metabolized by enzymes whose genes have inactivating polymorphisms [31]. 
Efforts to correlate genotype and phenotypebased traditional methodology of classifying humans into three major Prakriti types or constitutions described in Ayurveda have opened an exciting scientific chapter. They will help in the progress of individualized medicine approaches [32,33].

Herbal Medicine in China: Multisite mechanisms of action of herbal preparations from the crude extracts may offer higher chances for success where conventional single-site agents have been disappointing.

Novel Model for Integrative Healthcare: As Biomedicine does not succeed in offering desirable relief in certain diseases, the interest is increasing to find alternative solutions through integrative approaches by tapping the strength of both, Traditional Medicine and Biomedicine [34]. Regional traditional practices and cultural diversities require suitable models of integrative medicine to meet respective healthcare needs. China has successfully integrated traditional and modern practices by experimenting with ideas like barefoot doctors, herbal medicines, acupuncture, and modern medicine, working synergistically. Similarly, India may invent its own model to address various challenges, including the double burden of disease and the increasing gap between rich and poor, affordability, availability, and accessibility of health care. These challenges are confronted with other realities, including the limitations of modern therapy. Many psychosomatic and syndrome conditions do not have effective treatments except symptomatic relief. We need better, safer, and affordable treatments, especially for neglected diseases [35].

A true success and test of the 'integrative' approach will remain in the ability to recognize, respect, and maintain respective identities, philosophies, foundations, methodologies, and strengths intact while building a sufficient evidence base. We also must remember that "absence of evidence is not evidence of absence." We need to be little humble before criticizing or praising any system or monopolizing the science or evidence-based medicine. In all fairness, it is crucial to ensure that the required rigor of science is achieved without compromising the foundations of traditional practices and knowledge.

Although it may take some time to evolve a universal model of IM, in the larger interest of the global community, Indian and Chinese systems should share knowledge and experiences with the western medical world for mutual intellectual enrichments and collaboration to expedite this process. Such an "integrative" exercise is extremely delicate and sensitive almost like 'riding the tiger'. There is a chance of getting lost or carried away with the risk of losing identity. On the other side, there is a danger of getting swamped [36]. Let's hope that rather than a tiger-ride, a new model of integration actually becomes an elephant-ride to raise the vision, widen the horizons, and enhance the knowledge that ultimately benefits humanity.

The concept of integrative approach is gaining importance because of the growing focus on the necessity to offer patient-oriented treatment which may include more than one medical approach. To this end Biomedicine should be strengthened by creating awareness of Traditional Medicine science at appropriate levels of education [35]. Ayurveda is a comprehensive healthcare system that can easily be integrated into current national healthcare and therapies. The potential benefits associated with the integration of Ayurveda into mainstream medicine could include both greater patient satisfaction and a decrease in national healthcare costs. The potential benefits could also include addressing demands not met by orthodoxy and lack of consideration of the 'whole person.'

The foundation of Ayurveda, the Science (Veda) of Life (Ayus), is of an inclusive nature, as articulated by one of its founding fathers: 'The science of life shall never attain finality. Therefore, humility and relentless industry should characterize your endeavor and approach to knowledge. The entire world consists of teachers for the wise. Therefore, knowledge, conducive to health, longevity, fame and excellence, coming even from an unfamiliar source, should be received, assimilated and utilized with earnestness' [37].

Integrative Medicine: The integration model has resulted in some CAM techniques becoming mainstream, such as patient support groups [2]. A patient-centered partnership approach to 
healthcare may characterize integrative medicine, focusing on social, biological, spiritual, and psychological impacts to pathology, and an emphasis on providing education, hope, and therapeutic approaches that match an individual's worldview [6].

\section{DISCUSSION}

The arrival of globalization has augmented flow in all fields of science and technologies, taking healthcare systems to new heights of chance for the quick meeting of healthcare requirements [38]. The importance of research evidencebased practice is now accepted all over the world. The integration of taught disciplines is an important requirement of the modular curriculum. Medical students believe in the helpfulness of integrated curriculum, and the constructive feedback motivates students' insights of curricular invention, which has gained the acceptability $[39,40]$. Under the pretext of integration, attempts to make hybrid curricula producing inadequately trained graduates remain unacceptable for either modern or traditional systems [41].

Integrative MD Curriculum: A unique integration of Ayurveda and Biomedicine into one Medical Doctor education curriculum has been developed by the School of Integrative Medicine of the university Universidad Maharishi de Latino America y el Caribe (UMLAC), established in Curaçao, an island in the Caribbean. The goal of this School of Integrative Medicine is to fulfill the current global need to provide a holistic and scientific system of health care for prevention and cure, for both individual and collective health. In this regard Integrative Medicine is defined as a Patient-Centered Health Approach that uses modern medicine jointly with evidence-based Complementary and Alternative Medicine (CAM). In the case of UMLAC, it is based on Maharishi Ayurveda.

Maharishi Ayurveda: Maharishi Ayurveda is the ancient and timeless Vedic approach to medicine, which was brought to light in this scientific age for its authentic value of theory and practice by Maharishi Mahesh Yogi, in conjunction with the world's foremost experts in Ayurvedic Medicine and physicians and scientists in modern medicine. Maharishi Ayurveda is a comprehensive, scientific, prevention-oriented system of traditional medicine. It emphasizes the recent scientific discovery that consciousness - the Veda, the totality of Natural Law, or the Unified Field in the language of modern physics - is the basis of the physiology and medicine.

Treatment Modalities: Maharishi Ayurveda provides multiple treatment modalities and behavioral prescriptions to bring mind, body, behavior, and environment into harmony with the intelligence of nature and physiology, the natural and effective prevention and treatment of disease, and promotion of longevity. Maharishi Ayurveda takes into account all the levels that influence health, many of which are not usually considered by modern medicine. The purpose of all therapeutics is to enliven the body's inner intelligence, to promote homeostatic and selfrepair mechanisms.

At the level of the mind Maharishi Ayurveda utilizes Vedic technologies of consciousness, including the Transcendental Meditation (TM) program, the principal mind-body technique of Maharishi Ayurveda. During the practice, it is reported that ordinary thinking processes settle down, and a distinctive wakeful hypometabolic state characterized by neural coherence and physiological rest is gained [42].

Health approaches of Maharishi Ayurveda on the level of the body include as a main diagnostic method the pulse diagnosis-Nadi Vigyan in Sanskrit-that determines the state of the inner intelligence of the body, the level of balance or imbalance in the mind and body in order to detect imbalances early before they manifest as disease. Furthermore, on the level of the body Maharishi Ayurveda promotes health and prevent diseases through Ayurvedic Pharmacotherapy, traditional herbal formulas that nourish the natural structures and functions of the physiology rather than treating superficial symptoms. By using whole herbs that display the full range of biological intelligence, the ingredients of these herbal formulas function synergistically to maximize the health-promoting benefits. Other body approaches are neuromuscular integration (Yoga Asana) and breathing exercises (Pranayama) to increase flexibility and mindbody coordination. 
The profoundly rejuvenating Maharishi Ayurveda detoxification and rejuvenation treatment for the body, known as Panchakarma, is an integrated series of treatments and procedures that, taken together, dislodge impurities from the cells and tissues and cleanse the body of toxins and restore a healthy balance. Behavioral approaches to health from Maharishi Ayurvedic include lifestyles recommendations. According to psychophysiological type, each person is instructed in daily and seasonal health routines to maintain the integrity of key biologic rhythms.

Environmental factors influencing health found in Maharishi Ayurveda are Aroma therapy, used for protecting the vital force, prana, regulating digestion and metabolism, agni, and increasing resistance to disease, ojas; Vedic Organic Agriculture for healthy food; Vastu Architecture that proposes in detail how influences may be designed into a building to improve the quality of peoples' lives [43] ; and Jyotish and Yagya that provide the knowledge of influences on health by Sun, Moon, Planets and Stars through the trends of time and the means to avert future dangers. Such a broad scope to health as found in the traditional authentic Vedic texts is missing in modern medicine.

Goal: The goal of the proposed Integrative Medicine MD program is to prepare and empower the students to have the knowledge, skills, and attitude for prevention, diagnosis, and treatment of health issues by integrating the mind, body, behavior and environment, while becoming leaders who have the awareness to promote what is best for themselves and society.

Program Structure: The curriculum of the School of Integrative Medicine of UMLAC integrates the biological, social, behavioral, and clinical sciences over four years. During the first two years, the emphasis is placed upon the biological sciences, which are strictly correlated with the social and behavioral sciences. As the student progresses, the clinical sciences come to the fore. The venue of education transfers from the college campus to the multiple hospitals, clinics, and medical care facilities affiliated with the School.

Systemic Integrative Approach: The integration of Ayurveda into the Modern medicine curriculum is based on the following principles:

1. The eight major organ systems

2. The three-stage restoration cycle: balance (physiology) - imbalance (pathology) - recovery (pharmacology)

3. Integration of the content and of the learning process (teaching)

The program is based on a systemic curriculum of both, a Modern Medicine M.D. program and an Ayurvedic Medicine program. Each organ system is taught consecutively in the stage of balance (healthy), the stage of imbalance (disorder) and in the stage of recovery (treatment). The content of Modern Medicine and Ayurvedic Medicine is completely matched in terms of the topic. This is achieved by holding weekly three distinctive typical sessions: a Modern Medicine session discussing that week's part of the organ system, a session teaching the Ayurvedic knowledge related to that particular subject of the organ system and an integration session where that week's topics are being reviewed in small groups through a continuing case study on that organ system. This integration case study includes questions on the topics being discussed during that week in both sessions, the biomedicine and the Ayurveda class. For that reason, the integrative session should typically be coached by a practitioner trained in both systems, biomedicine and Ayurvedic medicine. So, in this integrative approach, the student is trained right from the beginning to have a patient-centered approach, from both systems what is best for the patient should be applied.

\section{CONCLUSION}

Ayurvedic medicine offers a wealth of economical healthcare therapies without the microbial resistance and adverse side effects often associated with modem drug therapy. Its treatments provide relief for many chronic illnesses for which modern medicine is still seeking a cure, including musculoskeletal disorders, rheumatoid arthritis, osteoarthritis, diabetes, obesity, and nervous disorders. With the availability of a truly integrative curriculum in Biomedicine and Ayurveda, medical schools can start offering integrative medicine programs without having to compromise on the requirements for a welltrained conventional doctor. Such an innovative 
undertaking will benefit the patients by broadening the public health care as well as governments who are seeking desperately for cost-effective measures,

The presented integrative model offers high potential for Western countries to respond to WHO's call to include traditional medicine into their health care system. The increasing use of traditional therapies demands more scientifically sound evidence for the principles behind therapies and the effectiveness of medicines. Recent advancements in the analytical and biological sciences, along with innovations in genomics and proteomics, can play an important role in the validation of these therapies. Western scientific community views traditional medicines cautiously and stresses the concerns related to research, development, and quality $[44,45]$. Novel efforts like Ayugenomics [46] aim to understand the Ayurvedic concept of Prakriti from the pharmcogenomics [47] view point. Finally, it emphasizes the importance of integrating medical curricula across the world integrating modern/conventional medicine with traditional, complementary, and alternative medicine.

\section{REFERENCES}

[1]. Klatt M, Moore K. Beyond the east/west dichotomy the course Yoga: theory and practice convey the benefits of an ayurvedic lens for global health. Glob Adv Health Med 2019;8. 2164956119847931. https:/ /doi.org/10.1177/2164956119847931 PMid:31106037 PMCid:PMC6501500

[2]. P.M. Barnes, B. Bloom, and R. L.Nahin. Complementary and Alternative medicine use among adults and children: United States, 2007. National health statistics reports 12, National Center for Health Statistics, Hyattsville, Md, USA, 2008. https://doi.org/ 10.1037/e623942009-001

[3]. National Institute of Health, U.S. National Library of Medicine, 2020.

[4]. National Institute of Health, National center for complementary and Integrative Health, 2020. Available at https://www.nccih.nih.gov/health/complementary-alternative-or-integrative-health-whats-ina-name

[5]. WHO global report on traditional and complementary medicine 2019.

[6]. I. R. Bell, O. Caspi, G. E. Schwartz et al. "Integrative medicine and systematic outcomes research: issues in the emergence of a new model for primary health care," Archives of Internal Medicine, 2002;162:133140. https://doi.org/10.1001/archinte.162.2.133 PMid:11802746
[7]. P. M. Barne, E. Powell-Griner, K. McFann, and R. L. Nahin. "Complementary and alternative medicine use among adults: United States, 2002," Advance Data, 2004;343:1-19. https://doi.org/10.1016/ j.sigm.2004.07.003

[8]. R. Snyderman and A. T. Weil. Integrative medicine: bringing medicine back to its roots. Archives of Internal Medicine, 2002;162(4):395-397. https:// doi.org/10.1001/archinte.162.4.395 PMid:11863470

[9]. D. Lie and J. Boker, "Development and validation of the CAM Health Belief Questionnaire (CHBQ) and CAM use and attitudes amongst medical students," BMC Medical Education, 2004;4(1):1-9. https:// doi.org/10.1186/1472-6920-4-2 PMid:14718061 PMCid:PMC373452

[10]. Patwardhan B. Traditional medicine: modern approach for affordable global health. Commission on Intellectual Property, Innovation and Public Health, World Health Organization, Geneva 2005.

[11]. Shankar D. Health sector reforms for 21st century healthcare. J Ayurveda Integrative Medicine 2015;6:4 9. https://doi.org/10.4103/09759476.154214 PMid:25878456 PMCid:PMC4395927

[12]. National Healthcare Disparities Report, 2011. Agency for Healthcare Research and Quality, USA. Available at https://www.ahrq.gov/research/findings/nhqrdr/index.html

[13]. Patwardhan B, Mashelkar RA. Traditional medicineinspired approaches to drug discovery: can Ayurveda show the way forward? Drug Discovery Today 2009;14:804-811. https://doi.org/10.1016/ j.drudis.2009.05.009 PMid:19477288

[14]. Patwardhan B, Mutalik G, Tillu G. Integrative approaches for health: biomedical research, Ayurveda, and Yoga. San Diego, USA: Academic Press, Elsevier Inc; 2015. https://doi.org/10.1016/B978-0-12801282-6.00012-7

[15]. Editorial. Ayur Yoga, the confluence of healing sciences: A call for global action. Journal of Ayurveda and Integrative Medicine 2019;10:79-80. https:// doi.org/10.1016/j.jaim.2019.06.001 PMid:31227145 PMCid:PMC6598802

[16]. Morris K. Meditating on yogic science. Lancet 1998; 351:1038. https://doi.org/10.1016/S01406736(05)79010-3

[17]. Garfinkel MS, Singhal A, Katz WA, Allan DA, Reshetar $R$, Schumacher HR Jr. Yoga-based intervention for carpal tunnel syndrome: a randomized trial. JAMA 1998; 280:1601-1603. https://doi.org/10.1001/ jama.280.18.1601 PMid:9820263

[18]. Bernardi L, Sleight P, Bandinelli G, Cencetti S, Fattorini L, Wdowczyc-Szulc J, et al. Effect of rosary prayer and yoga mantras on autonomic cardiovascular rhythms: comparative study. BMJ 2001; 323:14461449. https://doi.org/10.1136/bmj.323.7327.1446 PMid:11751348 PMCid:PMC61046

[19]. Cohen L, Warneke C, Fouladi RT, Rodriguez MA, Chaoul-Reich A. Psychological adjustment and sleep quality in a randomized trial of the effects of a 
Tibetan yoga intervention in patients with lymphoma. Cancer 2004;100:2253-2260. https://doi.org/ 10.1002/cncr.20236 PMid:15139072

[20]. Visweswaraiah NK, Telles S. Randomized trial of yoga as a complementary therapy for pulmonary tuberculosis. Respirology 2004; 9:96-101. https:// doi.org/10.1111/j.1440-1843.2003.00528.x PMid:14982609

[21]. Blanke O, Ortique S, Landis T, Seeck M. Stimulating illusory own-body perceptions. Nature 2002; 419:269-270. https://doi.org/10.1038/419269a PMid:12239558

[22]. Tong F. Out-of-body experiences: from penfield to present. Trends Cogn Sci 2003;7:104-106. https:// doi.org/10.1016/S1364-6613(03)00027-5

[23]. European committee for Homeopathy, 2020. Available at https://homeopathyeurope.org/homeopathyin-practice/benefits-of-homeopathy/

[24]. Ernst E. A systematic review of systematic reviews of homeopathy, Blackwell Science Ltd $\mathrm{Br}$ J Clin Pharmacol, 2002;54:577-582. https://doi.org/ $10.1046 / \mathrm{j} .1365-2125.2002 .01699$. PMid:12492603 PMCid:PMC1874503

[25]. Patwardhan, B. et al. Ayurveda and natural products drug discovery. Curr. Sci. 2004;86:789-799.

[26]. Patwardhan, B. (2005). Traditional Medicine: Modern Approach for Affordable Global Health. CIPIH Studies, WHO, Geneva. Available at http:// www.who.int/intellectualproperty/studies/ traditional_medicine/en/index.html

[27]. Nandakumar, D.N. et al. Curcumin-artemisinin combination therapy for malaria. Antimicrob. Agents Chemother. 2006;50:1859-1860. https://doi.org/ 10.1128/AAC.50.5.1859-1860.2006 PMid:16641461 PMCid:PMC1472230

[28]. Atal, C.K. et al. Biochemical basis of enhanced drug bioavailability by piperine: evidence that piperine is a potent inhibitor of drug metabolism. J. Pharmacol. Exp. Ther. 1985;232: 258-262.

[29]. Paul, A.T. et al. Modulating TNF-a signaling with natural products. Drug Discovery. Today 2006;11:725-732. https://doi.org/10.1016/ j.drudis.2006.06.002 PMid:16846800

[30]. Deocaris, C.C. et al. Merger of Ayurveda and tissue culture-based functional genomics: inspirations from systems biology. J. Transl. Med. 2008;6:1-8. https://doi.org/10.1186/1479-5876-6-14 PMid:18348714 PMCid:PMC2311278

[31].Relling, M.V. and Hoffman, J.M. Should pharmacogenomic studies be required for new drug approval? Clin. Pharmacol. Ther. 2007;81:425-428. https:// doi.org/10.1038/sj.clpt.6100097 PMid:17339872

[32]. Bhushan, P. et al. Classification of human population based on HLA gene polymorphism and concept of Prakriti in Ayurveda. J. Altern. Complement. Med. 2005;11:349-353. https://doi.org/10.1089/ acm.2005.11.349 PMid:15865503

[33]. Prasher, B. et al. Whole genome expression and biochemical correlates of extreme constitutional types defined in Ayurveda. J. Transl. Med. 2008;6:48.
[34]. Kumar, N.K, and Kumar Dua, P. Status of regulation on traditional medicine formulations and natural products: Whither is India? Current Science, 2016;111(2).

[35]. Patwardhan B. Planned progress for health. J Ayurveda Integr Med 2011; 2:161-162. https:// doi.org/10.4103/0975-9476.90762 PMid:22253502 PMCid:PMC3255443

[36]. Patwardhan B. Ayurveda and integrative medicine: riding a tiger. J Ayurveda Integr Med 2010;1:13-15. https://doi.org/10.4103/0975-9476.59820 PMid:21829294 PMCid:PMC3149384

[37]. Shankar D. Conceptual framework for new models of integrative medicine. Journal of Ayurveda and Integrative Medicine 2010;1:1-3. https://doi.org/ 10.4103/0975-9476.59817 PMid:21829291 PMCid:PMC3149389

[38]. Vader water DA. Best practice in Competence Assessment of Health Professionals. College of register Nurse of Nova Scotia;2004.

[39]. Rehman R, Iqbal A, Syed S, Kamran A. Evaluation of Integrated Learning Program of Undergraduate Medical Students, Pak J Physiol 2011;7(2):37-41.

[40]. Kalpana-Kumari MK, Vijaya V, Mysorekar, Raja S. Students' Perception about Integrated Teaching in An Undergraduate Medical Curriculum, Journal of Clinical and Diagnostic Research. 2011 November (Suppl-1);5(6):1256-9.

[41]. Department of Indian Systems of Medicines and Homoeopathy. Government of India. Annual Report 1999-2000.

[42]. Schneider, R.H., et al. Stress Reduction in the Secondary Prevention of Cardiovascular Disease. Randomized, Controlled Trial of Transcendental Meditation and Health Education in Blacks. Circulation: Cardiovascular Quality and Outcomes. 2012;5(6):750-758.

[43]. Maharshi Vastu Architecture, 2020. Available at https://www.maharishivastu.org/scientific-research

[44]. Patwardhan B, Chopra A, Vaidya ADB. Herbal remedies and the bias against Ayurveda. Curr Sci 2003;84:1165-1166.

[45]. Fabricant DS, Farnsworth NR. The value of plants used in traditional medicine for drug discovery. Environ Health Perspect 2001;109:69-75.

[46]. Patwardhan B. Ayugenomics: integration for customized medicine. Indian J Nat Prod 2003;19:1623.

[47]. Patwardhan B, Joshi K, Chopra A. Classification of human population based on HLA gene polymorphism and the concept of Prakriti in Ayurveda. J Altern Complement Med 2005; 11:349-53.

How to cite this article: Carl Camelia, Sateesh Babu Arja, Kumar Ponnusamy, Nimra Deivassagayame. NOVEL MODEL FOR INTEGRATIVE MEDICINE CURRICULUM. Int J Intg Med Sci 2020;7(7):931-939. DOI: 10.16965/ ijims.2020.114 